\title{
A ALOCAÇÃo dA RIQUEZA NA ZONA dA MATA MINEIRA. São Paulo do Muriahé, 1846-1888
}

\author{
Vitória Schettini de Andrade*
}

\begin{abstract}
RESUMO: Este trabalho terá a função de analisar a alocação da riqueza produzida em São Paulo do Muriahé, uma freguesia agrária da Zona da Mata mineira, durante meados à finais do século XIX. Para esta pesquisa, estaremos consultando os inventários post-mortem existentes no Fórum Tabelião Pacheco de Medeiros, em Muriaé, por acreditar que podemos abrir um debate para um maior entendimento desse espaço que antes da ocupação pelo homem branco era local reservado, principalmente, a negros fugitivos e a índios, conforme documentação analisada na matriz São Paulo. PALAVRAS-CHAVE: Riqueza; Aplicação; Economia; Zona da Mata mineira.
\end{abstract}

\section{The allocation of wealth in Zona da Mata mineira. São Paulo do Muriahé, 1846-1888}

ABSTRACT: The function of this essay is to analyze the allocation of wealth produced in São Paulo of Muriahé, an agrarian parish from "Zona da Mata Mineira", during the middle of the XIX centure. For this research, we will be consulting the post-mortem inventories existing in "Pacheco de Medeiros" Forum, in Muriaé, believing that we can open a debate for a greater understanding of this space, before the occupation by the with man was reserved, mainly, to fugitive black and native people, according to the documentation analyzed at the São Paulo`s main Church.

Keywords: Wealth; Economic application; Zona da Mata mineira.

\section{Asignación de riquezas en una parroquia de la Zona da Mata de Minas Gerais. Sao Paulo do Muriahé, 1846-1888}

RESUMEN: El trabajo consiste en analisar la distribución de la riqueza producida en Sao Paulo do Muriahé, una parroquia agraria de Minas Gerais ubicada en la zona de la mata mineira en el período de mediados hacia finales del siglo XIX. Para esta investigación, utilizaremos los archivos de los inventarios post-mortem del Foro Notarial Pacheco de Medeiros, en Muriaé, con el objetivo de mejor comprender este espacio. Antes de la ocupación del mismo por el hombre blanco, éste fue ocupado principalmente por una población formada por negros figitivos y indígenas, conforme demostran los datos analisados en la documentación en la Matriz Sao Paulo.

PALABRAS-CLAVE: Riqueza; Aplicación; Economía; Zona de la Mata.

\footnotetext{
* Doutora em Ciências Sociais em Desenvolvimento, Agricultura e Sociedade pela Universidade Federal Rural do Rio de Janeiro (UFRRJ). Pós-doutora em História pela Universidade do Minho/Portugal. Professora do Programa de Pós-graduação em História da Universidade Salgado de Oliveira e professora da Faculdade Santa Marcelina(FASM). Atualmente é professora na Unifaminas. Contato: Av. Cristiano Ferreira Varella, 655, Bairro Universitário, CEP: 36888-233, Muriaé-MG, Brasil. E-mail: vfschettini@yahoo.com.br.
} 


\section{Introdução}

"Mais importante do que constatar a permanência das fortes desigualdades sociais ao longo de quinhentos anos de Brasil é compreender que, nesses séculos a sociedade brasileira viveu mudanças (em suas relações sociais, nas formas de acumulação, no perfil de suas elites, etc)". ${ }^{1}$

É proposital, já na introdução deste artigo, citar as palavras de João Luís Fragoso, exatamente por observarmos que as explicações e entendimento sobre as mudanças na economia constituem um processo histórico de difícil compreensão. $\mathrm{O}$ autor salienta que para a percepção da brutal desigualdade na distribuição da riqueza, temos que entender historicamente o processo. Marcado por uma alta concentração de riqueza nas mãos de poucos, compartilhamos os valores originados de uma sociedade de predominância do trabalho escravo, em que foi produzido um contínuo fosso entre ricos e pobres.

Uma ciranda econômica acabaria por gerar alguma segurança em aplicações monetárias, de acordo com a temporalidade vivida. Para Fragoso ${ }^{2}$, a conversão de acumulação em fazendas confirma uma sociedade baseada no prestígio social, na qual as relações de poder estão além das relações de produção. Escravos e terras seriam um investimento seguro no período por ele recortado (1790-1830) na praça mercantil do Rio de Janeiro.

Em se tratando da Zona da Mata mineira, até pouco tempo, a região era vista como intermediária, de segundo plano, por estar localizada fora de eixo central das Minas Gerais. Os holofotes não estavam refletidos historicamente para a região leste da Província, até porque esta região, apresentou uma ocupação tardia se comparada às demais localidades do centro minerador mineiro. Tal fator influenciará decisivamente na justificativa de existirem poucos trabalhos que buscam aprofundar na economia da região, o que tem crescido de forma considerável nos últimos anos. Portanto, permanece ainda pequeno o número de pesquisas que se voltam para o leste da Mata mineira, designado por alguns como região central, área que será o foco deste trabalho. A maioria dos trabalhos se concentram nas proximidades de Juiz de Fora, chamada de região sul da Zona da Mata mineira e caracterizada por numa produção agrícola diversificada. ${ }^{3}$ Pelo que observamos, quanto mais tardia a ocupação e mais distante do eixo minerador, menores são as pesquisas até então realizadas.

Alguns desses estudos foram comentados em outra oportunidade, ${ }^{4}$ mas reforçamos a importância de pesquisas que abordem a Zona da Mata mineira como um todo e, para isto, o entendimento de cada freguesia se faz necessária. Trazer estudos regionais nos ajuda a 
compreender o emaranhado de ligações e redes entre os homens que por esta região circulavam. $^{5}$

A fim de entender essa região de forma mais profunda, este trabalho terá a função de analisar a alocação da riqueza produzida em São Paulo do Muriahé, uma freguesia agrária da Zona da Mata mineira, durante meados a finais do século XIX, momento em que notamos na documentação consultada um crescimento econômico, baseado principalmente na produção de gêneros agrícolas, como milho, cana de açúcar e mais tarde o café.

Para esta pesquisa, estaremos consultando os inventários post-mortem existentes no Fórum Tabelião Pacheco de Medeiros, em Muriahé, por acreditar que podemos abrir um debate para um maior entendimento desse espaço que antes da ocupação pelo homem branco era um local reservado, principalmente, aos negros fugitivos e aos índios, conforme documentação analisada no arquivo paroquial e nos cartórios locais.

A seguir, ilustraremos algumas pesquisas que ajudam a pensar a Zona da Mata mineira como um todo e que têm afinidade com o tema aqui proposto. Mais adiante, daremos ênfase ao trabalho desenvolvido por Rômulo Andrade, por fazer uma análise comparativa entre São Paulo do Muriahé e Juiz de Fora, o que é de vital importância para a compreensão da região em sentido mais amplo e, por fim, traremos uma análise dos resultados encontrados para esta pesquisa junto à documentação levantada.

\section{O pensar economicamente a Zona da Mata mineira}

Mônica Ribeiro de Oliveira ${ }^{6}$, ao estudar o sistema de transição para o sistema agrárioexportador, conclui que antes de uma mera extensão do sistema agrário fluminense, a cafeicultura mineira cresceu vinculada à acumulação endógena de capital mercantil na província, diferindo dos modelos do Rio de Janeiro, pela ausência de capitais de grosso trato nos primeiros investimentos e São Paulo, por transferir capitais anteriores ao cultivo de bens de subsistência ou exportação em atividades comerciais.

Verificando as fortunas de Juiz de Fora, entre os anos de 1870-1914, Rita de Cássia Almico ${ }^{7}$ afirma existir uma "dança de riqueza”, ou seja, a tríade escravos, dívida ativa e café eram os principais ativos econômicos do município no período escravista, mudando posteriormente após a abolição, principalmente, para terras, casas e títulos. E conclui que, “o capital acumulado graças à atividade econômica possibilitou grandes investimentos industriais e comerciais na região, demonstrando a diversificação da economia local e a formação de riquezas pessoais." 
Luiz Fernando Saraiva ${ }^{8}$ confirma essa análise de fortuna local, pelo menos no que se refere aos anos de 1870 a 1888, reforçando o que a historiografia já confirmara: uma estreita ligação entre a riqueza da região com o setor agrário. $\mathrm{O}$ autor separa os principais ativos ditos "rurais" ou ligados ao setor agroexportador e chega à conclusão que terras e escravos correspondiam a 55\% da riqueza total da região. O café permanecia numa média de $13,73 \%$, já o escravo correspondia, até o ano de 1887, a maior riqueza do período, isto é, $24,78 \%$ e as terras $16,49 \%$.

Para Jonis Freire, ${ }^{9}$ "em uma sociedade escravista, ser senhor de homens e de terras certamente determinava a riqueza de um indivíduo". Para o autor, existiam diferentes riquezas e que poderiam ser apresentadas de forma regional. Na fala do autor, "é importante ressaltar que as desigualdades regionais não devem ser desconsideradas, já que as diferenças socioeconômicas sem dúvida podem determinar padrões de riqueza diferenciados".

Anderson Pires ${ }^{10}$, partindo de um estudo sobre o capital agrário e investimento e crise na cafeicultura em Juiz de Fora, durante os anos de 1889 a 1930, constata que a base agroexportadora cafeeira favoreceu o desenvolvimento industrial e que a produção de café não entra em decadência após a abolição, permanecendo ativo durante muitos anos.

Wanderley Clarck dos Santos ${ }^{11}$, em pesquisas às cartas de alforria em São Paulo do Muriahé, esclarece que esta freguesia tem seu desenvolvimento ligado à economia agroexportadora cafeeira. Porém, a ascensão do café nesta localidade se deu mais tardiamente se comparado a Juiz de Fora, tendo por isso mesmo, uma estrutura de posse de escravos diferenciada, algo em torno de 1/3 da população escrava.

Conforme Mônica Ribeiro de Oliveira ${ }^{12}$, a expansão da produção cafeeira da Zona da Mata mineira teria ocorrido nas primeiras décadas do século XIX, acelerando a partir de 1850; todavia o grande auge produtivo aconteceu no início do século XX. De acordo com Anderson Pires $^{13}$, em 1847 e 1851, a Mata mineira obteve uma participação de quase 100\% proporcional à produção geral de café do Estado.

Ana Lanna ${ }^{14}$ afirma que, sendo a Zona da Mata mineira apenas 5\% do território do Estado de Minas Gerais, a região se beneficiou pela aproximação do Vale do Paraíba Fluminense, considerado anteriormente o maior produtor de café do país, como também por suas adequações ao produto. Pelas condições favoráveis, não tardou ser um dos principais centros comerciais exportadores da rubiácia, como descrito na tabela apresentada a seguir.

Baseado nos autores acima, vemos que a dinamização comercial da região se dá em função da agricultura que passa a ser seu carro chefe. Como é uma área que tem sua ocupação tardia, como visto anteriormente, para que houvesse este crescimento, era necessária uma 
preocupação maior com a mão de obra, com os programas de sementes, de mudas e de técnicas agrícolas. Era necessário cultivar a terra, bem como investir em benfeitorias e isto requeria tempo e investimentos. É neste cenário que surgem as primeiras plantações de cana, de mandioca, de milho e mais adiante o café, que se transformaria no maior produto exportador no final do século.

A tabela 1 nos permite vislumbrar uma participação ativa da região no que diz respeito à produção cafeeira mineira até 1926, permanecendo altíssimas as porcentagens de produção, com um pequeno declínio em 1886, 1903/04, queda oriunda principalmente dos cafezais do sul da província. Domingos Giroletti ${ }^{15}$ afirma que, em $1890,75 \%$ da receita do Estado adivinham das taxas da produção cafeeira. De 1870 a 1930, o café seria o responsável por cerca de $60 \%$ das exportações mineira.

Tabela 1: Relação Proporcional da Produção cafeeira da Zona da Mata na Produção do Estado de Minas Gerais (períodos selecionados)

\begin{tabular}{c|c|c|c}
\hline Período & Minas Gerais* & Zona da Mata* & \% \\
\hline $\mathbf{1 8 4 7 / 4 8}$ & 745.381 & 743.707 & $\mathbf{9 9 , 7 7}$ \\
\hline $\mathbf{1 8 5 0 / 5 1}$ & 900.264 & 898.184 & $\mathbf{9 9 , 7 6}$ \\
\hline $\mathbf{1 8 8 6}$ & 5.776 .866 & 4.316 .067 & $\mathbf{7 4 , 7 1}$ \\
\hline $\mathbf{1 8 8 8}$ & 5.047 .600 & 4.433 .800 & $\mathbf{8 7 , 8 3}$ \\
\hline $\mathbf{1 9 0 3 / 0 4}$ & 9.404 .136 & 5.993 .425 & $\mathbf{6 3 , 7 3}$ \\
\hline $\mathbf{1 9 2 6}$ & 12.793 .977 & 9.105 .543 & $\mathbf{7 1 , 1 7}$ \\
\hline
\end{tabular}

* em arrobas. Fonte: PIRES, 1993, p. 96.

A rápida expansão do mercado interno na região cafeeira repercutiu favoravelmente à produtividade do setor de subsistência ${ }^{16}$. Entretanto, diferentemente de Ana Lanna ${ }^{17}$, Mônica Oliveira $^{18}$ adverte que a Mata mineira gozava de capital internalizado na Província, o que ajudou na formação de um modelo autônomo de transição para o café. A cafeicultura mineira não dependeu de um avanço de fronteira ocidental da cafeicultura fluminense, sobretudo não dependeu da aplicação de capital mercantil e sim do capital produzido endogenamente na província, vinculada ao intercâmbio Centro/Sul que processou uma verdadeira mutação de categorias de produtores de alimentos, comerciantes e capitalistas, alçando a condição de grandes cafeicultores.

Mas nos perguntamos, Muriaé seguiu esta mesma característica da Zona da Mata mineira? Em que se baseavam as aplicações monetárias em um período de intensas 
transformações sociais, econômicas e culturais? Café, escravos, terras, benfeitorias faziam parte de tal designação? Tentaremos encontrar respostas para tais indagações a partir de análises documentais. E como citado anteriormente, chamaremos por riqueza o que foi acumulado durante toda a vida do inventariado, seguindo metodologicamente os trabalhos de Rita de Cássia Almico. ${ }^{19}$

\section{Ser rico em São Paulo do Muriahé: uma análise documental}

Necessário reforçar, como salientado em pesquisas anteriores ${ }^{20}$, que a região apontava para peculiaridades próprias: a existência de pequenos e médios proprietários, sem grandes plantations possuindo como sustentáculo econômico mão de obra escrava. Assim, na região, o que definia a posição socioeconômica era o número de cativos pertencentes à família. A terra não estava condicionada a este número de escravos, haja vista a quantidade de solo improdutivo resultando numa variável produção agrícola.

Procuramos vislumbrar as transformações advindas das aplicações monetárias das categorias que mais se destacavam nos inventários post-mortem, o que permitirá conhecer o grupo social que se sobressai e os interesses envolvidos nas relações instituídas. Para melhor conhecer esta realidade, apresentaremos a qualificação dos bens materiais e seus respectivos valores financeiros que constituíram a maioria das fortunas por nós analisadas. Através dos dados digitalizados dos inventários, catalogamos a parte referente ao montante de bens, que estão divididos em bens de raiz, semoventes (escravos), móveis e dívidas ativas. Após a catalogação, foi feita uma seleção dos principais geradores de riqueza através de cada montemor.

Em se tratando da freguesia analisada, Jamila Aparecida de Silva Câmara e Sérgio Antônio da Silva ${ }^{21}$ destacam a riqueza decorrida entre os anos de 1848 a 1888, sob uma perspectiva de cada 10 anos, e, na tentativa de diminuir o raio de ação, incluímos alguns inventários post-mortem que, na oportunidade, não compunham toda documentação analisada. Porém, antes de aprofundarmos neste estudo, de forma mais alargada, concentraremos nossos esforços para perceber esta variação na riqueza entre os anos de 1846 a 1865, como uma análise prévia e comparada usando uma metodologia diferenciada da que será abordada posteriormente. $^{22}$

Para tal pesquisa, selecionamos 89 amostragens de inventários, entre os anos de 1846 e 1865. Foram feitas uma média de cinco inventários/ano, num montante total de 56 
documentos descritos usando as seguintes categorias: escravos, benfeitorias/raiz, bens materiais (cobre, prata, ferro, utensílios e móveis), animais e dívidas ativas.

Do total analisado, 3,31\% da riqueza correspondia à quantidade de animais como burro, cavalo, boi, vaca, ovelha, cabra; $4,28 \%$ estariam entre os bens materiais; $5,27 \%$ em dívidas ativas; 40,98\% entre benfeitoria/raiz, incluindo engenhos, moinhos, chiqueiros, além de outros; e 46,16\% representavam a categoria de escravos, como mostra o gráfico a seguir.

Gráfico 1: Alocação da riqueza em São Paulo do Muriahé e região (1846-1865)

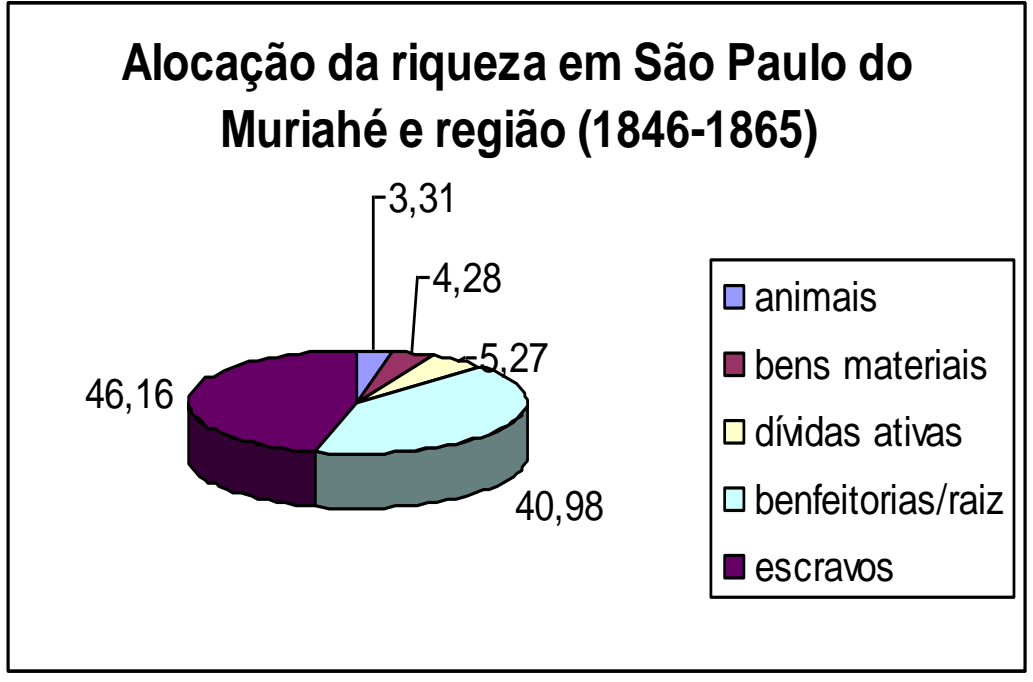

Fonte: SALVADOR, 2008, p. 12.

No decorrer da pesquisa notamos uma variação resultante do ano de 1850 . De acordo com Lígia Osório Silva ${ }^{23}$, a Lei de Terras, constitucionalizadas nesse ano, influenciou na economia local, mudando parte das estruturas econômicas existentes. Todavia, tal transformação só refletiu de forma convincente em Muriahé e região a partir de 1858.

A Lei Euzébio de Queiroz colocou fim ao comércio internacional de escravos, mas de certa forma colaborou com o tráfico proibido e interprovincial, o que encareceu o preço dos escravos. Estes preços que eram em média $800 \$ 000$ (oitocentos mil réis) nos anos iniciais da pesquisa, passaram em 1858 para 2:000\$000 (dois contos de réis). Um aumento considerável que resultou em várias transformações e até mesmo em falência de alguns cafeicultores locais, que, sem dinheiro para investir em mão de obra escrava, acabariam por sofrer um colapso. Tal fator contribuirá diretamente para os dados apresentados, por ser nítido a influência do período para a variação dos negócios efetuados.

Se observarmos um desmembramento feito entre os anos de 1846 a 1865, para 1846 a 1858 e ainda 1859 a 1865, notamos que as transformações não refletiam apenas os valores dos 
escravos, mas também a economia local. Os bens materiais que até 1858 correspondiam a $9,68 \%$ da riqueza local, agora representavam 1,02\%. Os animais e dívidas ativas se mantiveram reguláveis, já que as terras também presenciavam um grande aumento em seu valor, conforme os gráficos a seguir.

Gráfico 2: Alocação da riqueza em São Paulo do Muriahé e região (1846-1865)

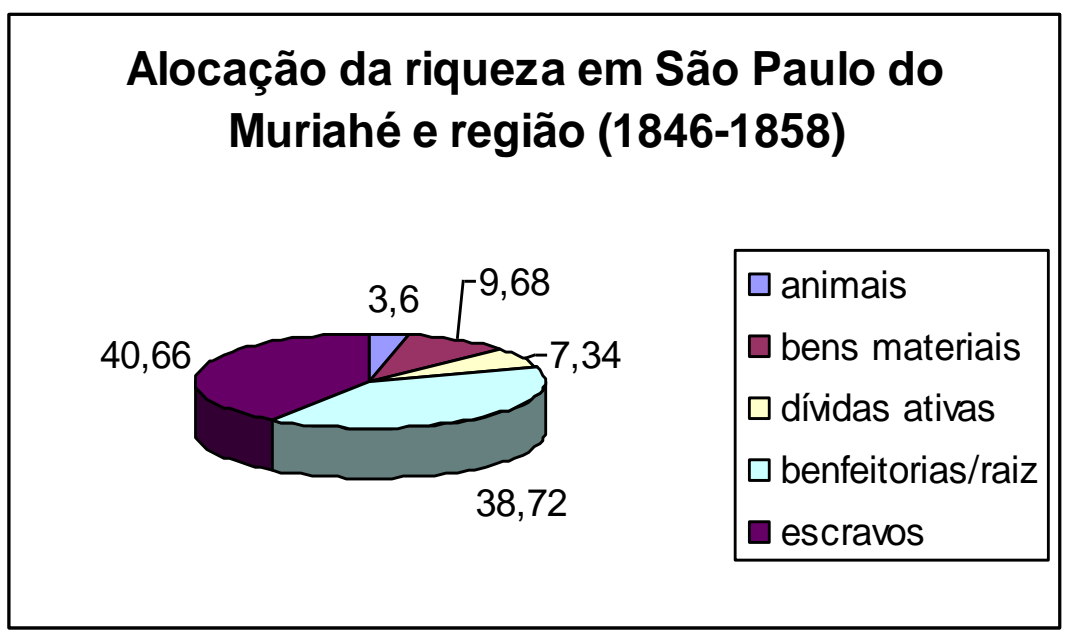

Fonte: SALVADOR, 2008, p. 13.

Gráfico 3: Alocaçção da riqueza em São Paulo do Muriahé e região (1859-1865)

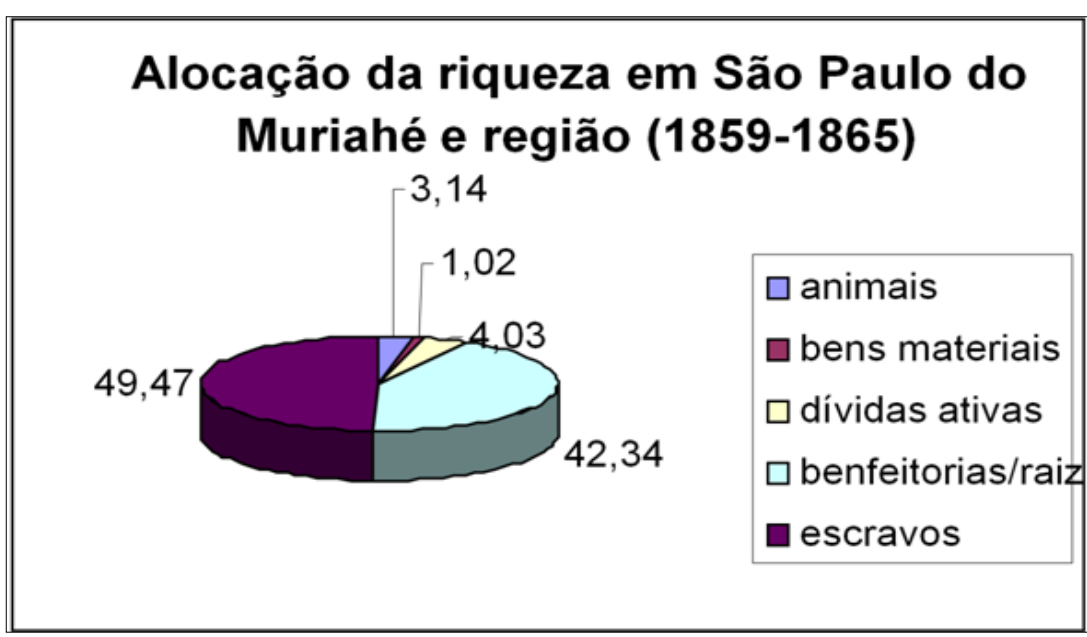

Fonte: SALVADOR, 2008, p. 13.

As pesquisas de Rômulo Garcia Andrade ${ }^{24}$, apesar de ser apresentado com um recorte e uma metodologia diferenciada, não distanciam muito dos dados alcançados. Ao fazer um estudo contábil levando em consideração as inversões significativas para o processo produtivo, tais como: escravo, terra e café, salienta-nos que, entre os anos de 1872 a 1884, os 
escravos representavam mais da metade das inversões, seguidos da terra e do café. Outra nota feita pelo autor é que havia pouca representatividade dos pequenos proprietários no conjunto de inversões, uma vez que, os grandes e médios concentravam mais de $90 \%$ delas, o que justifica historicamente ser uma sociedade extremamente desigual em sua distribuição de renda. Poucos detinham a maioria das terras e lucros, enquanto, a grande maioria vivia em péssimas condições econômicas, conforme mostra a tabela abaixo.

Tabela 2: Os proprietários rurais de Muriahé e a concentração de escravos, terra e café, 1872-84

\begin{tabular}{l|l|l|l|l|l}
\hline \multicolumn{1}{c|}{ Proprietários } & \multicolumn{1}{c|}{$\mathbf{N}^{\mathbf{0}}$} & \multicolumn{1}{c|}{ Escravos } & \multicolumn{1}{c}{ Café } & \multicolumn{1}{c}{ Terras } & \multicolumn{1}{c}{ Total } \\
\hline Pequenos & 10 & $34: 194(10 \%)$ & $8: 640(8 \%)$ & $18.686(8 \%)$ & $61: 520(9 \%)$ \\
\hline Médios/grandes & 10 & $314: 495(90 \%)$ & $96: 770(92 \%)$ & $209.280(92 \%)$ & $620: 545(91 \%)$ \\
\hline Total & $\mathbf{2 0}$ & $\mathbf{3 4 8 : 6 8 9}(\mathbf{1 0 0 \%})$ & $\mathbf{1 0 5 : 4 1 0}(\mathbf{1 0 0 \%})$ & $\mathbf{2 2 7 . 9 6 6 ( 1 0 0 \% )}$ & $\mathbf{6 8 2 : 0 6 5 ( 1 0 0 \% )}$ \\
\hline
\end{tabular}

Fonte: ANDRADE, 1995, p. 63

Numa comunidade agrícola, onde o sistema escravista era o sustentáculo dessa moldura econômica, o trabalho escravo tinha o papel primordial na economia do período ${ }^{25}$. Assim, expandir a produção implicava em primeiro lugar, o aumento do plantel de escravos $^{26}$, seguido de outras duas características fundamentais, a terra e o cafe $^{27}$, como nos mostra a tabela abaixo.

Tabela 3: Comparações das inversões em escravos, terra e café. Murihé, 1872-84

\begin{tabular}{c|c|c|c|c}
\hline Proprietários & Escravo & Café & terras & total \\
\hline Pequenos & $56 \%$ & $14 \%$ & $30 \%$ & $100 \%$ \\
\hline Médios/Grandes & $51 \%$ & $16 \%$ & $33 \%$ & $100 \%$ \\
\hline
\end{tabular}

Fonte: ANDRADE, 1995, p. 63.

Desta forma, independente do lucro obtido com a produção das terras, possuir maior número de cativos era o que definia a posição econômica e social dos moradores locais, ou seja, a terra não estava condicionada ao número de escravos e muito menos à produção agrícola.

Rômulo Andrade ${ }^{28}$ afirma que a média de anotações sobre pés de café por propriedades em Muriaé era de aproximadamente 21.300 pés, sendo que 50.000 foram a maior quantidade encontrada em uma propriedade. Conquanto, é importante esclarecer que o 
tamanho das propriedades era extenso, mas a sua produtividade não ultrapassava feições de pequeno produtor. Acreditamos que o número de pés de café apontado por Andrade deve ser revisto, pois, ao verificar o inventário de um dos maiores proprietários de escravos da região, Desembargador Antônio Augusto da Silva Canêdo, encontramos números que ultrapassam a maior quantia encontrada pelo referido autor, qual sejam, 102 mil pés de café; e ainda, 5.250 arrobas de café em coco; 600 arrobas de café novo e 300 arrobas de café em frutas, além das culturas de arroz, feijão, milho, cana-de-açúcar, mandioca e arroz, o que provavelmente implica num aumento da produção local do produto $^{29}$.

A localidade analisada teve como característica a base de concentração de terras, onde a pequena minoria dominava a grande extensão de terra, ainda que, o número de escravos e a dedicação à cafeicultura fossem muito modestos. Assim, as pequenas e médias propriedades tinham a função de absorver o grande contingente populacional de escravos que existia na localidade no século XIX. As aplicações monetárias trazidas por Andrade possuem afinidades com os dados que serão aqui apresentados, na qual estenderemos o raio temporal de ação. Anteriormente, focalizávamos os anos de 1846 a 1865, agora estenderemos nossa análise para os anos de 1846 a 1888. Porém, vamos aprofundar a variação da riqueza de tempo em tempo para melhor analisar as mudanças nas aplicações monetárias em um maior espaço temporal.

Como observado anteriormente, o declínio da área de mineração dispersa a população de suas minas em busca de novas terras e afazeres, levando à ocupação dos Sertões do Leste. As Matas, com suas características propícias para o cultivo do café, vislumbraram as novas formas de riqueza e a construção da base econômica do novo polo comercial mineiro, que seria um grande atrativo para aventureiros em busca de novas explorações econômicas. $\mathrm{O}$ crescimento das lavouras trouxe para a região outra fonte de riqueza segura para a época, $a$ mão de obra escrava. Paralelos aos escravos, as terras se apresentam como a mais segura fonte de investimentos e a mais consistente do sistema econômico para o período mencionado, persistindo até o limiar da escravidão, abrindo novos caminhos para a última forma de riqueza dos proprietários do final do século XIX e início do XX: o café.

Para melhor conhecer esta realidade, apresentamos a qualificação dos bens materiais e seus respectivos valores financeiros que, construirão a maioria das grandes fortunas por nós analisadas: escravos, terras e café; buscando assim analisar a variação da riqueza no município de São Paulo do Muriahé, no século XIX. Para esta próxima etapa da pesquisa, os inventários post-mortem continuam sendo nossa principal documentação equivalente ao período entre 1848 a 1888, perfazendo um total de 190 documentos. Através dos dados digitalizados dos inventários, catalogamos a parte referente ao montante de bens, que estão 
divididos em: bens de raiz, semoventes (escravos), móveis e dívidas ativas. Após a catalogação foi feita uma seleção dos principais geradores de riqueza através de seus representativos no monte-mor. Foram estabelecidas comparações entre esses dados, a fim de avaliar a variação na riqueza em recortes de 10 anos.

No primeiro período analisado, entre os anos de 1850-1859, os escravos representaram $49,22 \%$ da riqueza total, as terras $44,01 \%$ e café $6,77 \%$ dos inventários, perfazendo um total de 97:920\$000. Distribuídos entre 48:200\$000, aplicados em escravos, 43:100\$000, em terras e 6:620\$000 investidos em café, conforme o gráfico abaixo.

Gráfico 4: Análise dos bens. São Paulo do Muriahé, 1850-1859

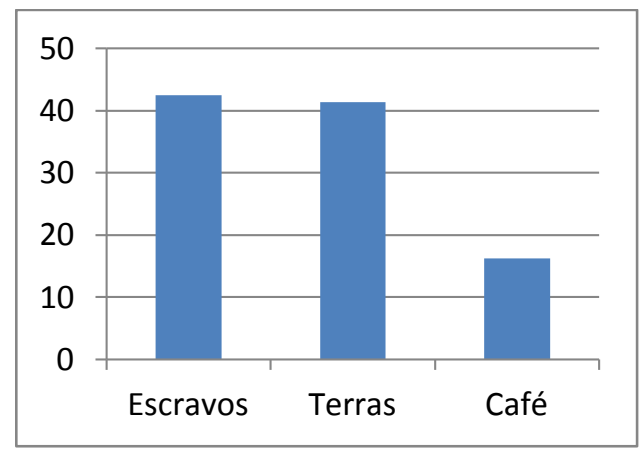

Fonte: Inventários post-mortem, 1850-1859. FTPM, Muriaé - MG.

Entre os anos de $1860-1869$, os cativos apresentam $63,05 \%$, as terras $34,71 \%$ e o café figura em 2,24\%, num total de 93:648\$825, sendo aplicados 59:050\$000 em escravos, 32:514\$825 em terras e 1:900\$000 em café.

Gráfico 5: Análise dos bens. São Paulo do Muriahé, 1860-1869

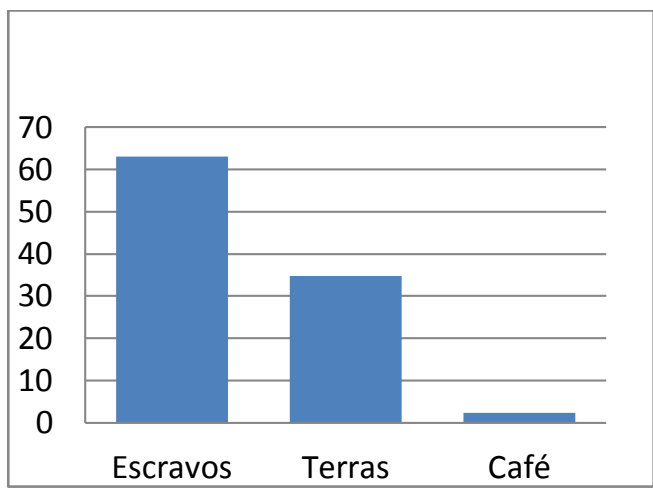

Fonte: Inventários post-mortem, 1860-1869. FTPM, Muriaé - MG.

No período entre os anos de 1870-1879, os escravos figuram 52,65\%, terras representarão $36,67 \%$ e o café, $10,68 \%$ do montante dos inventários aplicados entre 
308:283\$000. Dentre os investimentos 75:700\$000 são em escravos, 43:100\$000 em terras e 15:600\$000 em café.

Gráfico 6: Análise dos bens. São Paulo do Muriahé, 1870-1879

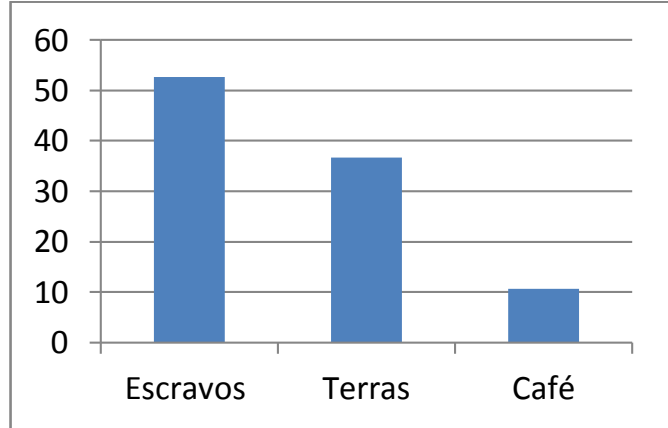

Fonte: Inventários post-mortem, 1870-1879. FTPM, Muriaé - MG.

Nos anos entre 1880-1888, os cativos representaram $42,49 \% \%$, as terras giravam em torno de $41,34 \%$ e o café $16,17 \%$ do total da riqueza, aplicados à soma de 377:360\$391, distribuídos ente 160:340\$000 em escravos, 156:016\$191 em terras e 61:004\$200 em café.

Gráfico 7: Análise dos bens. São Paulo do Muriahé, 1880-1888

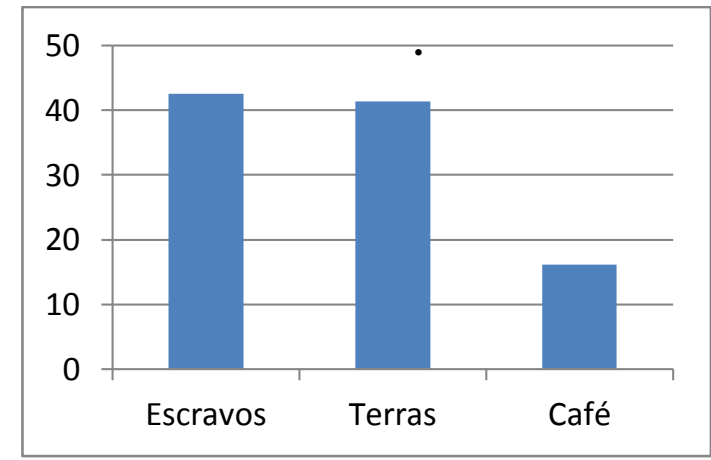

Fonte: Inventários post-mortem, 1880-1889. FTPM, Muriaé - MG.

Com base na análise dos dados catalogados, referentes aos inventários post-mortem do Fórum Tabelião Pacheco de Medeiros, nota-se que a riqueza pessoal em São Paulo do Muriahé era basicamente composta pela posse de escravos, seguido das terras e café, havendo um crescimento gradativo entre terra e café, enquanto o preço do escravo tem um declínio no último período analisado. Nos anos de 1880 a 1888, o valor da terra aproxima-se do escravo tendo o café permanecido inexpressivo para o recorte temporal em todos os períodos analisados, muito embora houvesse um crescimento da produção rubiácea em todos os períodos avaliados. Ao que tudo indica, a partir de 1888, o café teria uma intensificação na 
produção favorecido pelo escoamento da produção, via estrada de ferro, que chega a freguesia em 1886, estando ligada à situação econômica dos grandes cafeicultores, o que poderá ser um dos fatores responsáveis pela urbanização e um incentivo ao crescimento local.

Muito embora a região se caracterizasse por baixos plantéis de escravos, este grupo, em todos os períodos analisados, permanece sendo o do maior valor aplicável, inclusive até os períodos finais da escravidão, mesmo em períodos de intensas mudanças econômicas, seguidos de uma crescente valorização da terra.

A terra inserida ao meio da produção cafeeira retrata sua variação de preços e instabilidade econômica, mediante ao cativo que somente no último período (década de 1880), próximo à abolição, terá seu valor comercial um pouco reduzido no mercado, comparado aos períodos anteriores. O valor da terra passa de $40 \%$ nos inventários analisados no último recorte (1880-1888) retornando sua importância financeira, observada nas primeiras décadas (1850/1859), em que perfazia um total de 44,01\% do valor total dos inventários analisados, junto aos escravos com 49,22\% e o café apresentando 6,77\% do total de 48:200\$000 na primeira década analisada.

Afirmamos, assim como Rita Almico ${ }^{31}$, uma “dança de riqueza" nas aplicações monetárias, porém, necessário se faz esmiuçar os dados para tentar fugir ao modelo já tradicional: terra, café e escravos, a fim de verificar mudanças na própria estrutura que aos poucos se organiza em Muriaé. O aumento do valor das terras pode ser entendido como uma forma de controle dos fazendeiros, revelando como uma das aplicações mais seguras em períodos de mudança, apesar de não ser até finais da escravidão o principal bem aplicável.

Mesmo não sendo objetivo principal deste trabalho, merece destaque o número de dívidas ativas apresentadas na documentação e poucas dívidas passivas, o que demonstra certo equilíbrio monetário entre os inventariados. Apenas em caráter ilustrativo e tentando perseguir trajetórias individuais, selecionamos o inventário de maior investimento e bens encontrado. Um registro datado de 20 de maio de 1883, do inventariado Desembargador Antônio Augusto Bicalho Canêdo. Com uma riqueza fora dos padrões normais para a freguesia, o documento consta com aparatos de uma banda de música, café, cana de açúcar, feijão, potes de água ardente, capados, garrotes, bestas, seleiros, casas de vivenda, olarias, 103 escravos (101 escravos residentes na freguesia murieense e 2 escravos residentes em Barbacena), etc. Ainda no documento observa-se um número gigantesco de dívidas ativas, cerca de 313:540\$00 (Trezentos e treze contos, quinhentos e quarenta mil réis) dentre as dívidas ativas estão o Banco do Brasil, Companhia de Seguros, Apólices, Eudóxia Canêdo (a 
esposa), os filhos, padres, dentre outros, e nenhuma dívida passiva, o que demonstra que o Desembargador era realmente um investidor estável residente na região. ${ }^{32}$

Tabela 4: Composição de bens de Antônio Augusto da Silva Canêdo- 1883

\begin{tabular}{ccc}
\hline Bens & Valor & $\%$ \\
\hline Móveis & $9: 127 \$ 000$ & 1,8 \\
Semoventes & $6: 340 \$ 000$ & 1,1 \\
Escravos & $99: 600 \$ 000$ & 19,6 \\
Raiz & $79: 153 \$ 000$ & 15,6 \\
Joias & $884 \$ 480$ & 0,1 \\
Dívidas & & \\
ativas & $313: 540 \$ 000$ & 61,8 \\
Total & $506: 644 \$ 000$ & 100 \\
\hline
\end{tabular}

Fonte: FTPM. Inventários post-mortem do Desembargador Antônio Augusto Bicalho Canêdo, 1883, Maço 55.

Ainda no mesmo inventário, observa-se que só na freguesia de São Paulo do Muriahé, excluindo Barbacena, uma soma total 506:644\$000 dentre escravos, terras e café, e outros bens. Portanto, há de se notar que dentre os herdeiros, seis filhos eram do segundo matrimônio: Antônio (17 anos), Balbina (9 anos), Agenor (8 anos), Affonso (5 anos) Christianno (3 anos), Guilhermina (8 meses); e quatro filhos de primeiras núpcias: D. Augusta Canêdo Alves Pequeno casada com Dr. Augusto Pinto Alves Pequeno; D. Christina Severina Augusta Canêdo de Magalhães casada com Augusto de Almeida Magalhães; D. Antônia Augusta Canêdo Penna casada com Domingos Moreira Teixeira Penna, o que de fato poderia contribuir para a redução dos bens com a divisão e partilha entre os herdeiros.

\section{Considerações Finais}

Esperamos que a análise dos dados acima levantados tenha contribuído para um maior entendimento do que era considerado ser rico na freguesia São Paulo do Muriahé no século XIX. Fica nítido que a economia estava em crescimento e mesmo que apresente um modelo tido como tradicional, já que estes dados se aproximam de outra freguesia da Mata mineira, como apontado por Rita Almico e também do modelo fluminense, como descrito por João Fragoso, outras aplicações monetárias são percebidas ao final da escravidão, como aplicações em ações e abertura de bancos, o que nos projeta para uma sociedade em franca mudança e crescimento. 
Assinalamos ainda que, em São Paulo do Muriahé, não foi o café a mola propulsora para a ocupação e crescimento da freguesia, mesmo entendendo que a rubiácea seria a grande impulsionadora do crescimento urbano em finais do século XIX. Isso porque a riqueza estava concentrada na presença da mão de obra escrava, que mais adiante dividiria este espaço com a terra e ao final da escravidão com o café. Pelo menos, até 1875, os geradores de renda, que mais tarde seriam aplicados na produção da rubiácea, estariam concentrados em atividades oriundas da agricultura, principalmente do milho e da cana de açúcar. Estes produtos foram fundamentais para o acúmulo de capital e o ingresso de Muriahé numa economia mais dinâmica.

Chamou-nos atenção, após esta análise, não apenas as variações monetárias que gerariam o equilíbrio financeiro do senhor, mas como estes bens se concentram nas mãos de poucas pessoas. Claro que um maior entendimento das mudanças sofridas economicamente no período recortado necessita de uma ampliação e análise pós-1888 e ainda um cruzamento desta fonte analisada com os registros de notas para melhor vislumbrar este cenário. Portanto, não temos dúvidas de que a região caminhava rumo a novos tempos. A cidade crescia. Os determinantes sociais e econômicos tomavam direções antes não existentes, novos investimentos se manifestavam e consequentemente só acirraria o fosso entre ricos e pobres, que de fato marcou a sociedade brasileira historicamente construída.

\section{Notas}

\footnotetext{
${ }^{1}$ FRAGOSO, João L. Para que serve a História Econômica? Estudos Históricos. Rio de Janeiro, n ${ }^{\circ}$ 29, 2002, p 3-28.

${ }^{2}$ FRAGOSO, João L. Homens de grossa aventura: acumulação mercantil e hierarquia na praça mercantil do Rio de Janeiro. Rio de Janeiro: Arquivo Nacional, 1992.

${ }^{3}$ Para entender as regiões da Zona da Mata mineira, ver CARRARA, Ângelo Alves. Estruturas e capitalismo: contribuição para o estudo da ocupação do solo e da transformação do trabalho na Zona da Mata mineira, séc. XVII e XIX. Série Estudos, n², Mariana: NHED/UFOP, 1999. p.13.

${ }^{4}$ Para maiores detalhes, ver ANDRADE, Vitória Fernanda Schettini de. Os sertões de São Paulo do Muriahé: Terra, riqueza e família na Zona da Mata mineira, 1846-1888. Tese de Doutorado em Ciências Sociais em Desenvolvimento, Agricultura e Sociedade. Universidade Federal Rural do Rio de Janeiro/CPDA, 2011.

${ }^{5}$ Em conversa com Dr ${ }^{a}$ Elione Silva Guimarães, observamos que um dos maiores proprietários de escravos da região, Manoel Garcia de Mattos, era oriundo de Juiz de Fora, filho de Francisco Garcia de Mattos, um grande senhor de escravos morador de Juiz de Fora. Claro que Manoel Garcia de Mattos não se deslocou de Juiz de Fora sem saber das possibilidades econômicas existentes em Muriaé, demonstrando que havia intensas trocas econômicas, social, cultural, dentre outras, entre familiares de um local e outro. Ver: BRAGA, Tiago de Castro. Família, Riqueza e Sociabilidade na Zona da Mata mineira: Os Garcia de Mattos na segunda metade do século XIX. Dissertação de Mestrado em História. Niterói: Universo, 2017.

${ }^{6}$ OLIVEIRA, Mônica Ribeiro de. Negócios de família. Mercado, terra e poder na formação da cafeicultura mineira - 1780-1870. Bauru, SP: Edusc: Juiz de Fora, MG: Funalfa, 2005. p.249.

7 ALMICO, Rita de Cássia. Fortunas em Movimento: as mudanças ocorridas na riqueza pessoal. Juiz e Fora, 1870-1914. Dissertação de Mestrado. Campinas: Unicamp, 2001.
} 
${ }^{8}$ SARAIVA, Luiz Fernando. Um corredor de casas, antigas senzalas: a transição do trabalho escravo para o livre em Juiz de Fora, 1870/1900. Dissertação de Mestrado. UFF/Niterói, 2001.

${ }^{9}$ FREIRE, Jonis. Composição da riqueza em grandes propriedades do sudeste escravista, Minas Gerais século XIX. In. Fronteiras, Dourados, MS, v. 11, n. 19, p. 299-326, jan./jun. 2009.p. 310.

10 PIRES, Ânderson José. Capital Agrário, Investimento e Crise na Cafeicultura de Juiz de Fora - 1870. Dissertação de Mestrado em História. Niterói: UFF, 1993.

${ }^{11}$ SANTOS, Wanderley Clark. "As cartas de alforria e sua ambiguidade na re-invenção da liberdade (Zona da Mata de Minas Gerais, século XIX). Monografias de Curso de Especialização em História do Brasil, Departamento de História/Universidade Federal de Juiz de Fora, 1997.

12 OLIVEIRA, Mônica Ribeiro de. Negócios de família. Mercado, terra e poder na formação da cafeicultura mineira - 1780-1870. Bauru, SP: Edusc: Juiz de Fora, MG: Funalfa, 2005.

${ }^{13}$ PIRES, Ânderson José. Capital Agrário, Investimento e Crise na Cafeicultura de Juiz de Fora - 1870. Dissertação de Mestrado em História. Niterói: UFF, 1993.

${ }^{14}$ LANNA, Ana. A organização do trabalho livre na Zona da Mata Mineira, 1870-1920. Anais do V Encontro da Associação Brasileira de Estudos Populacionais/ABEP, 1986.p.30-31.

15 GIROLETTI, Domingos Antônio. Modernização Capitalista em Minas Gerais - A formação do operariado industrial e de uma nova cosmovisão. Tese de Doutorado. Rio de Janeiero: PPGAS/UFRJ, 1987.

${ }^{16}$ FRAGOSO, João L. Homens de grossa aventura: acumulação mercantil e hierarquia na praça mercantil do Rio de Janeiro. Rio de Janeiro: Arquivo Nacional, 1992. p.976:46)

${ }^{17}$ LANNA, Ana. A organização do trabalho livre na Zona da Mata Mineira, 1870-1920. Anais do V Encontro da Associação Brasileira de Estudos Populacionais/ABEP, 1986.

${ }^{18}$ OLIVEIRA, Mônica Ribeiro de. Negócios de família. Mercado, terra e poder na formação da cafeicultura mineira - 1780-1870. Bauru, SP: Edusc: Juiz de Fora, MG: Funalfa, 2005.

19 ALMICO, Rita de Cássia. Fortunas em Movimento: as mudanças ocorridas na riqueza pessoal. Juiz e Fora, 1870-1914. Dissertação de Mestrado. Campinas: Unicamp, 2001.

${ }^{20}$ Para maiores detalhes ver Andrade, Rômulo Garcia (1995) e Andrade, Vitória Fernanda Schettini de (2006)

21 CÂMARA, Jamila Aparecida Silva; ALMEIDA, Sérgio Antônio de Paula. Análise dos inventários post mortem da comarca de São Paulo do Muriahé, 1848-1888. Iniciação Científica. Fafism: Muriaé, 2009.

${ }^{22}$ Nos basearemos em um estudo desenvolvido em parceria com Antônio Anardino Salvador. SALVADOR, Antônio Anardino. Analise econômica de Muriaé e região, sob uma perspectiva demográfica. (1846-1865). In: $2^{\circ}$ Seminário de História Econômica e Social da Zona da Mata Mineira. Muriaé/Fafism, Outubro, 2008. CD Rum.

${ }^{23}$ SILVA, Lígia Osório. Terras devolutas e latifúndio. Efeitos da lei de 1850. Ed Unicamp: Campinas, 1996.

${ }^{24}$ Limites impostos pela escravidão à comunidade escrava e seus vínculos de parentesco: Zona da Mata de Minas Gerais, século XIX. (A subjetividade do escravo perante a coisificação social própria do escravismo) Tese de doutorado. USP. São Paulo, 1995. p.93.

${ }^{25}$ LIBBY, Douglas Cole. Trabalho escravo e capital estrangeiro no Brasil: o caso de Morro Velho. Belo Horizonte: Itatiaia, 1984.p.15.

${ }^{26}$ ANDRADE, Rômulo Garcia. Família escrava e estrutura agrária nas Minas Gerais oitocentista. Revista População e Família. no 1, p.181-210, jan-jun. São Paulo: Humanitas/CEDHAL, 1998.p.186.

${ }^{27}$ Limites impostos pela escravidão à comunidade escrava e seus vínculos de parentesco: Zona da Mata de Minas Gerais, século XIX. (A subjetividade do escravo perante a coisificação social própria do escravismo) Tese de doutorado. USP. São Paulo, 1995. p. 61.

${ }^{28}$ Limites impostos pela escravidão à comunidade escrava e seus vínculos de parentesco: Zona da Mata de Minas Gerais, século XIX. (A subjetividade do escravo perante a coisificação social própria do escravismo) Tese de doutorado. USP. São Paulo, 1995. p.43.

${ }^{29}$ Inventário Desembargador Antônio Augusto da Silva Canêdo. Maço 55. FTPM, Muriaé.

${ }^{30}$ Para o período analisado, o inventário do Desembargador Antônio Augusto Bicalho Canêdo corresponde a $51,77 \%$ do montante do valor para os itens: Escravos, Terra e Café perfazendo um total de 195:371\$385 (Cento e noventa e cinco contos, trezentos e setenta e um mil, trezentos e oitenta e cinco réis).

31 ALMICO, Rita de Cássia. Fortunas em Movimento: as mudanças ocorridas na riqueza pessoal. Juiz e Fora, 1870-1914. Dissertação de Mestrado. Campinas: Unicamp, 2001. 


\section{Referências Bibliográficas}

ALMICO, Rita de Cássia. Fortunas em Movimento: as mudanças ocorridas na riqueza pessoal. Juiz e Fora, 1870-1914. Dissertação de Mestrado. Campinas: Unicamp, 2001.

ANDRADE, Rômulo Garcia. Família escrava e estrutura agrária nas Minas Gerais oitocentista. Revista População e Família. $\mathrm{n}^{\mathrm{o}}$ 1, p.181-210, jan-jun. São Paulo: Humanitas/CEDHAL, 1998.

Limites impostos pela escravidão à comunidade escrava e seus vínculos de parentesco: Zona da Mata de Minas Gerais, século XIX. (A subjetividade do escravo perante a coisificação social própria do escravismo) Tese de doutorado. USP. São Paulo, 1995.

ANDRADE, Vitória F Schettini de. Um olhar sobre o espaço histórico e geográfico de São Paulo do Muriahé: conflitos e redes de sociabilidades. In. SOUSA, Jorge Prata e ANDRADE, Rômulo Garcia (Orgs). Zona da Mata Mineira: fronteira, escravismo e riqueza. - 1. ed. - Rio de Janeiro: Apicuri, 2014.

Os Sertões de São Paulo do Muriahé: Terra, Riqueza e Família na Zona da Mata Mineira 1846-1888. Universidade Federal Rural do Rio de Janeiro, Tese de Doutorado: Seropédica, 2011.

. Batismo e apadrinhamentos de filhos de mães escravas. São Paulo do Muriahé, 1850-1888. Dissertação de Mestrado: USS. Vassouras, 2006.

BRAGA, Tiago de Castro. Família, Riqueza e Sociabilidade na Zona da Mata mineira: Os Garcia de Mattos na segunda metade do século XIX. Dissertação de Mestrado em História. Niterói: Universo, 2017.

CÂMARA, Jamila Aparecida Silva; ALMEIDA, Sérgio Antônio de Paula. Análise dos inventários post mortem da comarca de São Paulo do Muriahé, 1848-1888. Iniciação Científica. Fafism: Muriaé, 2009.

CARDOSO DE MELLO, Zélia M. Metamorfoses da riqueza. São Paulo, 1845-1895. São Paulo: Hucitec, 1985.

CARRARA. Ângelo Alves. Estruturas agrárias e capitalismo: contribuição para o estudo da ocupação do solo e da transformação do trabalho na zona da mata mineira, século XVIII e XIX. Série Estudos, no 2, Mariana: NHED/ UFOP, 1999.

FRAGOSO, João L. Para que serve a História Econômica? Estudos Históricos. Rio de Janeiro, $\mathrm{n}^{\circ}$ 29, 2002, p 3-28.

Homens de grossa aventura: acumulação mercantil e hierarquia na praça mercantil do Rio de Janeiro. Rio de Janeiro: Arquivo Nacional, 1992.

FREIRE, Jonis. Composição da riqueza em grandes propriedades do sudeste escravista, Minas Gerais século XIX. In. Fronteiras, Dourados, MS, v. 11, n. 19, p. 299-326, jan./jun. 2009.

GIROLETTI, Domingos Antônio. Modernização Capitalista em Minas Gerais - A formação do operariado industrial e de uma nova cosmovisão. Tese de Doutorado. Rio de Janeiro: PPGAS/UFRJ, 1987.

LANNA, Ana. A organização do trabalho livre na Zona da Mata Mineira, 1870-1920. Anais do V Encontro da Associação Brasileira de Estudos Populacionais/ABEP, 1986.

LIBBY, Douglas Cole. Trabalho escravo e capital estrangeiro no Brasil: o caso de Morro Velho. Belo Horizonte: Itatiaia, 1984.

OLIVEIRA, Mônica Ribeiro de. Negócios de família. Mercado, terra e poder na formação da cafeicultura mineira - 1780-1870. Bauru, SP: Edusc: Juiz de Fora, MG: Funalfa, 2005.

PIRES, Ânderson José. Capital Agrário, Investimento e Crise na Cafeicultura de Juiz de Fora - 1870. Dissertação de Mestrado em História. Niterói: UFF, 1993. 
SALVADOR, Antônio Anardino. Analise econômica de Muriaé e região, sob uma perspectiva demográfica. (1846-1865). In: $2^{\circ}$ Seminário de História Econômica e Social da Zona da Mata Mineira. Muriaé/Fafism, Outubro, 2008. CD Room.

SANTOS, Wanderley Clark. "As cartas de alforria e sua ambiguidade na re-invenção da liberdade (Zona da Mata de Minas Gerais, século XIX). Monografias de Curso de Especialização em História do Brasil, Departamento de História/Universidade Federal de Juiz de Fora, 1997.

SARAIVA, Luiz Fernando. Um corredor de casas, antigas senzalas: a transição do trabalho escravo para o livre em Juiz de Fora, 1870/1900. Dissertação de Mestrado. UFF/Niterói, 2001.

SILVA, Lígia Osório. Terras devolutas e latifúndio. Efeitos da lei de 1850. Ed Unicamp: Campinas, 1996. 